\title{
Paying research subjects: participants' perspectives
}

Margaret L Russell, Donna G Moralejo and Ellen D Burgess University of Calgary, Canada

\begin{abstract}
Objective-To explore the opinions of unpaid healthy volunteers on the payment of research subjects.

Design-Prospective cohort.

Setting-Southern Alberta, Canada.

Participants-Medically eligible persons responding to recruiting advertisements for a randomised vaccine trial were invited to take part in a study of informed consent at the point at which they formally consented or refused trial participation. Of 72 invited, 67 (62 trial consenters, 5 trial refusers) returned questionnaires at baseline and 54 at follow-up. Outcome measures-Proportions of persons who agreed or disagreed with three close-ended statements on the payment of research subjects; themes and categories identified by content analysis of responses to an open-ended question.

Results - A minority (43.3\%) agreed with paying either patient or healthy volunteer participants. Opinions did not change over time. Participants' comments addressed: benefits and drawbacks to research participation; benefits and drawbacks to paying research participants; conditions under which payment of research subjects would be acceptable, and the nature of acceptable recognition. Acceptable conditions were to improve problematic recruitment, to reimburse costs, and to recognise participants, particularly for their time investment. Both non-monetary and monetary recognition of volunteers were thought to be appropriate. Conclusions-Most unpaid volunteers disagreed with paying research participants. The themes arising from their comments are similar to those that have been raised by ethicists and suggest that recognising the time and effort of participants should receive greater emphasis than presently occurs.

(Fournal of Medical Ethics 2000;26:126-130)
\end{abstract}

Keywords: Ethics, medical; human experimentation; clinical trials; voluntary workers

\section{Introduction}

Financial compensation is an important reason for many people to take part in clinical studies: healthy volunteers, ${ }^{1-5}$ those who are symptomatic, ${ }^{67}$ and those considering participation in a hypothetical study. ${ }^{3}$ In spite of the dem- onstrated importance of financial compensation as a motivator, ethicists and regulatory bodies have raised ethical concerns related to paying subjects to caution against, and even restrict, its widespread use. ${ }^{8-10}$ Since there is little information from research participants themselves regarding whether or not research subjects should be paid, we explored the opinions of healthy volunteers on payment for research participation.

\section{Methods}

Data for this exploration of research subjects' opinions on payment were obtained as part of a study of the process of informed consent. Participants in this study were medically eligible persons who responded to a call for volunteers for a separate randomised vaccine trial conducted in Southern Alberta. They were invited to take part in the informed consent/payment study at the point at which they formally consented or refused participation in the vaccine trial. The volunteers had been recruited through: 1) newspaper advertisements, 2) posters in public places, physicians' offices and public health immunisation clinics, 3) an advertisement on the World Wide Web, and 4) by post office and electronic mailings to persons listed in the investigators' volunteer database. There was no payment for taking part in the vaccine trial; however reimbursement for studyrelated parking and long-distance telephone charges was available.

Data for this study were collected via selfadministered questionnaire. Trial consenters were given two questionnaires, one at enrolment and the second at the time of their last trial clinic visit, one to two months after trial enrolment. Two reminders were sent. Trial refusers were sent a baseline questionnaire at the time they expressed their decision, and a follow-up questionnaire one month later with no reminders. Respondents were asked to return the anonymous questionnaire by mail within 24 hours of receipt. Items relevant to the present analysis addressed demographic information, self-reported health status, past research experience (for example, "Have participated in other research studies") and occupation 
Table 1 Numbers and proportions of respondents who agreed/disagreed with statements about paying research subjects

\begin{tabular}{|c|c|c|}
\hline Statement & $\begin{array}{l}N \text { Who agree } \\
(\%)\end{array}$ & $\begin{array}{l}N \text { Who } \\
\text { disagree (\%) }\end{array}$ \\
\hline $\begin{array}{l}\text { Participants should be permitted } \\
\text { to be paid for their time } \\
(\mathrm{N}=65)\end{array}$ & $22(33.8 \%)$ & $43(66.2 \%)$ \\
\hline $\begin{array}{l}\text { Participants should only be paid if } \\
\text { they are healthy volunteers } \\
(\mathrm{N}=63)\end{array}$ & $15(23.8 \%)$ & $48(76.2 \%)$ \\
\hline $\begin{array}{l}\text { Patients who have a disease for } \\
\text { which they are in a study } \\
\text { should be paid for their time } \\
(\mathrm{N}=64)\end{array}$ & $17(26.6 \%)$ & $47(73.4 \%)$ \\
\hline Any of the above $(N=64)$ & $29(43.3 \%)$ & $38(56.7 \%)$ \\
\hline All three statements $(\mathrm{N}=62)$ & $9(14.5 \%)$ & $38(61.3 \%)$ \\
\hline
\end{tabular}

(for example, "Have worked or am now working in a health profession such as medicine or nursing"). Three close-ended questions on payment of research subjects (listed in table 1) were scored on four-point agree/disagree scales. There was also an open-ended question: "Please add any thoughts or comments you may have about payment for research participation".

Numeric data were double-entered, validated and analysed using frequencies and cross tabulations in Epi Info, version 6.04 b. $^{11}$ Text data were typed on a word processor and analysed qualitatively, using codes developed from the written comments. Themes were identified from the coded responses.

\section{Results}

DESCRIPTION OF RESPONDENTS

Of 72 persons given questionnaires, 67 (93.1\%) returned baseline questionnaires (62 trial consenters, 5 trial refusers). Fifty-four of these 67 respondents also returned follow-up questionnaires ( 53 trial consenters, 1 trial refuser). Of the five persons who did not return either questionnaire, one was a trial consenter and four were trial refusers.

Respondents ranged in age from 22-52 years (median 39 years), and $41(61.2 \%)$ were female. Respondents were highly educated: $40.3 \%$ had one or more university degrees, including two persons with degrees in either medicine, dentistry, optometry or veterinary medicine. Forty-one per cent had experience of working in a health profession. Ten per cent had research experience. The vast majority $(80.6 \%)$ classified their health as excellent or very good, and none rated it as poor. Trial refusers and trial consenters were similar with respect to demographic characteristics, working in health care, past research experience, self-reported health status and education.
Table 2 Themes unrelated to payment

\begin{tabular}{ll}
\hline Major theme & Categories \\
\hline Benefits to study participation & $\begin{array}{l}\text { Benefits to society } \\
\text { Psychological benefits to participant } \\
\text { Physical benefits to participant }\end{array}$ \\
$\begin{array}{l}\text { Dime consuming } \\
\text { participation }\end{array}$ & $\begin{array}{l}\text { Financial costs to participant } \\
\text { Inconvenience } \\
\text { Discomfort } \\
\text { Injury }\end{array}$ \\
\hline
\end{tabular}

OPINIONS ON PAYING RESEARCH PARTICIPANTS

A minority of respondents (43.3\%) agreed with paying research subjects under any of the three scenarios offered in the questionnaire's statements (table 1). Opinions were not associated with sex, trial participation, working in health care, prior experience with research, or educational attainment. However, those who disagreed with all three statements were slightly older (mean $=45$ years versus 43 years; $p=0.02$ ) than were those who agreed with any of the statements. Opinions did not significantly change between baseline and follow-up.

Comments were provided by 35 persons (33/62 trial participants; $2 / 5$ trial refusers) at baseline and 18 trial participants at follow-up. Those who provided comments were similar to those who did not with respect to demographic characteristics and previous research experience. Making comments was associated with opinions on paying research subjects among both trial consenters and trial refusers. Over half $(51.6 \%)$ of subjects who made comments, in contrast to only $25.8 \%$ of those who did not make comments, agreed with one or more of the statements on paying research subjects.

COMMENTS NOT DIRECTLY RELATED TO PAYMENT

Respondents clearly identified both the benefits and drawbacks of study participation. Table 2 lists the three categories of comments identified within the major theme of benefits of study participation: benefits to society (for example, "participate in advancement of knowledge", "benefit others"); psychological benefits to the participant (for example, "contribute ... to the success of the research"), and physical benefits to the participant (for example, "getting free vaccines").

Comments on the drawbacks of participation fell into five categories, also listed in table 2: 1) time requirements, 2) financial costs to the participant, 3) inconvenience, 4) discomfort and 5) injury. Respondents commented that participation required a "non-trivial amount of time". Costs that were mentioned included "costs incurred to the participant ... parking ... travel", and "baby-sitting". One respondent stated that 
participation could be inconvenient. Others commented on "significant discomfort" from study procedures. Concerns about injury are illustrated by the following comment: "in the past some research subjects (ie, Montreal LSD study) have developed extreme long term illness as the result of drug studies ...".

Two responses at follow-up seemed to have some legal element to them. One respondent said she would not need to be paid for participation "as long as a detailed consent form was supplied and detailed information about the study and risks and benefits were provided". She had written about the need for detailed consent forms in the baseline response, but had not linked consent to payment at baseline. Another respondent said it was important that the intervention was "well tested prior to experimenting on healthy people". This participant had, at baseline, written about a duty to participate providing risks were minimal.

COMMENTS RELATED TO PAYMENT

Of the 35 persons who provided comments at baseline, 14 made comments that were clearly against paying research subjects. A few suggested that respondents perceived there was a moral duty for people to volunteer rather than to require payment: "People should volunteer because they want to help. Not because they will receive a fee!". "Providing the study has very limited/or minimal risks, I feel it is our duty to participate in the advancement of knowledge without any monetary incentives."

Many of the comments were not easily categorised as being clearly for or against payment of research subjects. For example, one respondent's comments indicated that she was for payment to "make research more interesting", yet she strongly disagreed with each of the three statements about payment of research subjects. Other responses indicated that payment would have been appreciated but was not necessary.

Overall, respondents' comments pertaining to payment could be related to four themes, listed in table 3:1) benefits of paying subjects, 2) problems with paying subjects, 3 ) conditions under which it would be acceptable to pay subjects, and 4) the nature of the recognition to be provided. The themes were similar at both baseline and followup. Only four of the 10 persons with prior research experience made relevant comments: "being paid or rewarded somehow may make research more interesting to others", "if recruitment became a problem ... [payment] could become an option", "it is always nice to be paid for my time", "[don't advertise payment] ... give honorarium after they complete all levels of the study that they can ...
Table 3 Themes related to payment

\begin{tabular}{|c|c|}
\hline Major theme & Categories \\
\hline Benefits to paying participants & $\begin{array}{l}\text { Increase study recruitment } \\
\text { Recognises participants }\end{array}$ \\
\hline $\begin{array}{l}\text { Problems with paying } \\
\text { participants }\end{array}$ & $\begin{array}{l}\text { Bias study results } \\
\text { Induce unethical behaviours } \\
\text { Increase costs of research } \\
\text { Increase cost of end product to } \\
\text { consumers }\end{array}$ \\
\hline $\begin{array}{l}\text { Conditions under which } \\
\text { payment acceptable }\end{array}$ & $\begin{array}{l}\text { Improve problematic study } \\
\text { recruitment } \\
\text { More equitable participation } \\
\text { Reimburse study related } \\
\text { expenses } \\
\text { Compensate subjects for injury } \\
\text { Recognition of participants }\end{array}$ \\
\hline $\begin{array}{l}\text { Nature of recognition to be } \\
\text { provided }\end{array}$ & $\begin{array}{l}\text { Non-monetary } \\
\text { Monetary }\end{array}$ \\
\hline
\end{tabular}

then you still have volunteers and you are recognising them". Their comments were consistent with the comments of those without prior research experience.

PROBLEMS WITH PAYING PARTICIPANTS

Four potential problems with payment of research subjects were clearly identified (table 3 ). The first related to bias in study results: "If people are only doing research to get paid, I would have to question the accuracy of their results". Some comments related to more than one category. For example, the comment: "People might give any answer or false data just to be eligible for the study and get the money" seemed to relate both to the potential for bias in study results and to the second category of the induction of unethical behaviours. Examples of other comments related to unethical behaviour included: "Cash for volunteering scams/frauds ...", "May unduly influence some to participate and therefore voids ... freedom of choice ... " and "Result in unethical behaviour in participants and/or researchers". The third category addressed increasing the cost of research, for example: "not as much research could be done if payment is required". The final category related to increases in the costs of the end product to consumers, for example: "Paying participants would only elevate the cost of the end [drug] product".

BENEFITS OF PAYMENT AND CONDITIONS WHEN IT WOULD BE ACCEPTABLE

In their comments, respondents identified two benefits of paying participants (table 3): increasing study recruitment, and recognition of participants. Acknowledgment of the benefits did not seem to equate with unqualified agreement with payment, however, since respondents identified conditions under which it would be acceptable to pay research subjects. As shown in table 3, there seemed to be five categories of such conditions. 
The first condition, increasing problematic recruitment for a study, was mentioned by several persons, for example: "if a particular study is not getting volunteer interest, some incentive may need to be provided". Other respondents seemed to be more focused upon the issue of equitable participation: "Individuals with less education and of lower socioeconomic status do not recognise potential benefits of studies ... . In instances where [these people] could benefit ... incentive of payment may be warranted", and from another person: "some occupations should be compensated to get a broad range of participants ie, busy professionals". Respondents also thought that participants should be reimbursed for study-related expenses, for example, "if travel is required, or costs incurred to the participant such as parking etc, these could be paid by the study". The fourth category related to compensation for injury, for example: "[if illness/ injury from study participation] cost of the treatment and damages relating to quality of life alterations", and "[if study causes harm] ... compensation ... for suffering and for injury...".

The final category focused on the recognition of participants: "everybody's time is worth something". Other examples of comments in this category included: "[compensate those who don't receive medical benefit] for their time and effort"; "By their employers - use of work time to benefit society as a whole", and "Consider tax receipt for 'donation' at value equivalent to 'payment for time' for participants (nominal amount). Allows for recognition of time/effort of participant".

NATURE OR RECOGNITION TO BE PROVIDED

Comments indicated that the nature of the recognition to be provided to research subjects could be categorised as non-monetary, and monetary (table 3). Examples of non-monetary recognition included: "Study intervention itself-for example, free vaccine", and "token gift". Suggestions for monetary recognition included "dollars" as well as the more creative "tax receipt for 'donation' at value equivalent to payment for time".

\section{Discussion}

Ethicists and professional bodies have expressed concerns regarding the payment of participants in clinical research. ${ }^{81213}$ Many investigators ${ }^{1-7}$ have evaluated the importance of payment as a motivator for consenting to take part in clinical studies. We have taken a different and unusual approach: that of asking actual research participants themselves if people should be paid for joining in clinical research. In their questionnaire responses, the majority of respondents disagreed with the payment of research subjects regardless of whether the subjects are healthy volunteers or patients, and responses were generally stable over the short study period. That most were not in favour of payment is perhaps not surprising as our sample consisted of unpaid volunteers, in contrast to the previously cited studies of the motivations of participants who were paid to take part in clinical research. Further, many of our subjects worked in health professions where there may be a perception of moral duty to assist in advancing knowledge in the health sciences.

In their comments, the respondents identified potential problems with paying research subjects, including undue pressures to participate, bias and the impact on costs. These concerns have been raised by several authors, including ethicists, researchers and regulatory agencies. ${ }^{891315}$ The subjects recognised that payment could increase recruitment, and thought it justifiable if recruiting for a study was a problem. However, some comments also seemed to suggest it was justifiable even when recruitment was not a problem, in order to ensure more equitable recruitment across social strata, so that poorer persons should have a chance to benefit from research, and to ensure that more advantaged persons also participated. This is interesting because many of the concerns about payment as inducement have focused on the burdens of research rather than potential benefits of participation; and of undue inducements for poor persons. ${ }^{1215}$

A key finding from this study was that respondents distinguished between paying subjects as an incentive for participation, payment of expenses incurred by participants, compensation for injury and payment as recognition of the participant's time and effort. The latter three seemed to be more acceptable than the first, as most respondents who discussed payment as incentive clearly stipulated increased recruitment as a situation where such payment might be acceptable. These distinctions have been delineated in the published literature addressing payment of research subjects. ${ }^{812} 15$ We do not think these distinctions arose as a result of past research experience, as only four persons with past research experience provided comments, their comments addressed only two of the themes, and the same themes arose in the comments of others.

The findings raise the question as to whether researchers should place more emphasis on the ethical principle of respect for persons by recognising the time and effort taken by subjects. The current application of this principle focuses on informed consent as the means of promoting 
respect by ensuring full disclosure and the right to self-determination. The principle of justice would also argue in the direction of increasing recognition for the time and effort of subjects, for at least some studies, as suggested by the comments of our respondents. Recognition need not necessarily be monetary in nature. Participation by both higher and lower socioeconomic subjects might be increased if subjects were to be compensated for their time - ie, an offer of payment might reduce rather than increase inequities in participation. It has also been suggested that monetary payment may be required simply to represent fairness to subjects who agree to participate in a study when the development of profitable commercial products is the expected outcome. ${ }^{16}$

This study is limited by its relatively small sample size and the inclusion of only unpaid participants, although the very high response rate ensures that the data obtained should provide an unbiased assessment of the opinions of the study sample. The high level of educational attainment of our sample is very unrepresentative of the population at large, and indeed of the total pool of potential participants that we had hoped to attract for the vaccine trial. Thus, our findings may not be generalisable. In addition, the nature of the data collection restricted the depth to which issues identified could be explored. However, our study was exploratory rather than hypothesis-testing in nature. Future research should explore the opinions of both paid and unpaid healthy volunteers, of patients, and of the public at large, thereby addressing the issue of generalisability. Emphasis would need to be placed not only on whether or not to pay research subjects, but also on the distinctions noted between payment as incentive, as reimbursement and as recognition.

\section{Conclusion}

Less than $45 \%$ of the subjects in this study, unpaid volunteers, agreed with paying research participants. Their comments indicated that they recognised the benefits and potential problems associated with payment, and clearly distinguished payment as incentive from payment of expenses or payment as recognition. The themes arising from their comments were similar to those raised by ethicists who have addressed this topic. The findings also suggest that, rather than focusing primarily on payment as potentially coercive, both researchers and institutional ethics boards should consider expanding the interpretation of the principles of respect for persons and justice, and placing an increased emphasis on recognising the time and efforts of the participants in clinical research.

\section{Acknowledgement}

The authors would like to thank the Endowment Fund, Faculty of Medicine, University of Calgary for funding this project.

Margaret L Russell, MD, PhD, FRCPC, is Associate Professor in the Department of Community Health Sciences, Faculty of Medicine, University of Calgary, Canada. Donna $G$ Moralejo, RN, MSc (A), is a Doctoral Candidate in the same department. Ellen $D$ Burgess, MD, FRCPC, is Professor in the Department of Medicine, Faculty of Medicine, University of Calgary.

\section{References}

1 Hassar M, Pocelinko R, Weintraub M, Nelson D, Thomas G, Lasagna L. Free-living volunteer's motivations and attitudes toward pharmacologic studies in man. Clinical Pharmacology and Therapeutics $1977 ; 21: 515-19$

2 Whinnery JE. Motivational analysis of human volunteers for centrifuge acceleration research. Aviation, Space and Environmental Medicine 1982;53:1017-20.

3 Bigorra J, Baños JE. Weight of financial reward in the decision by medical students and experienced healthy volunteers to participate in clinical trials. European fournal of Clinical Pharmacology 1990;38:443-6.

4 Vrhovac R, Francetic I, Rotim K. Drug trials on healthy volunteers in Yugoslavia. International fournal of Clinical Pharmacology, Therapy and Toxicology 1990;9:373-9.

5 van Gelderen CEM, Savelkoul TJE, van Dokkum W, Meulenbelt J. Motives and perception of healthy volunteers who participate in experiments. European fournal of Clinical Pharmacology 1993;45:15-21.

6 Aby JS, Pheley AM, Steinberg P. Motivation for participation in clinical trials of drugs for the treatment of asthma, seasonal allergic rhinitis, and perennial non-allergic rhinitis. Annals of Allergy, Asthma and Immunology 1996;76:348-54.

7 Allergy, Asthma and Immunology 1996;76:348-54. informed consent: a qualitative study of drug trial participants. Fournal of the American Board of Family Practitioners 1996;9:1422.

8 Royal College of Physicians. Research on healthy volunteers, a report of the Royal College of Physicians. Fournal of the Royal College of Physicians of London 1986;20:243-57.

9 Therapeutics Products Directorate, Health Canada. ICH harmonized tripartite guideline: international conference on harmonisation of technical requirements for registration of pharmaceuticals nisation of technical requirements for registration of pharmaceuticals for human use. Good climical practice: consolidated guideline. Available from URL: http://www.hc.gc.

10 Tri-Council Working Group. Code of ethical conduct for research involving humans. Available from URL: http:// www.mrc.gc.ca/ethics/code/english/toc.html

11 Dean AG, Dean JA, Coulombier D, Brendel KA, Smith DC, Burton $\mathrm{AH}$, et al. Epi info, version 6: a word-processing, database, and statistics program for public health on IBMcompatible microcomputers. Atlanta, Georgia: Centers for Disease Control and Prevention, 1995

12 De Castro LD. Exploitation in the use of human subjects for medical experimentation: a re-examination of basic issues. Bioethics 1995;9:259-68.

13 Vere DW. Payments to healthy volunteers - ethical problems. British fournal of Clinical Pharmacology 1991;32:141-2.

14 Darragh A, Kenny M, Lambe R, Brick I. Sudden death of a volunteer. Lancet 1985;1:93-4.

15 Ackerman TF. An ethical framework for the practice of paying research subjects. IRB: A Review of Human Subjects Research 1989;11:1-4.

16 Rudy EB, Estok PJ, Kerr ME, Menzel L. Research incentives: money versus gifts. Nursing Research 1994;43:253-5. 